\title{
Reasoning, Proof and Proving in Mathematics Education
}

\author{
Viviane Durand-Guerrier
}

\section{Overview}

The work of TSG 14 intended to serve a dual role: presentation of the current state of the art in the topic "Reasoning, proof and proving in mathematics education" and expositions of outstanding recent contributions to it. The topic will be considered at all levels of education: elementary, secondary, university (including pre-service teacher education), and in-service teacher education. The Organizing Team of the Study Group had invited theoretical, empirical or developmental papers that address one or more of the following themes: Historical/Epistemological/logical issues; Curriculum and textbook aspect; Cognitive aspect; Teaching and teacher education aspect, so that any paper of relevance to the overall focus of the Study Group.

The role and importance assigned to argumentation and proof in the last decade has led to an enormous variety of approaches to research in this area. Historical, epistemological and logical issues, related to the nature of mathematical argumentation and proof and their functions in mathematics, represent one focus of this wide-ranging research. Focus on mathematical aspects, concerning the didactical transposition of mathematical proof patterns into classrooms, is another established approach, which sometimes makes use of empirical research. Most empirical research focuses on cognitive aspects, concerning students' processes of production of conjectures and construction of proofs. Other research addresses implications for the design of curricula, sometimes based on the analysis of students' thinking in arguing and proving and concerns about didactical transposition. Recent empirical

Organizers Co-chairs: Maria Alessandra Mariotti (Italy), Stéphane Cyr (Canada); Team Members: Andreas Stylianides (UK), Viviane Durand-Guerrier (France), Youngmee Koh (Korea), Kirsti Hemmi (Sweden); liaison IPC member Hee Chan Lew (Corea).

\footnotetext{
V. Durand-Guerrier $(\bowtie)$

University of Montpellier, Montpellier, France

e-mail: vdurand@math.univ-montp2.fr

(C) The Author(s) 2015

S.J. Cho (ed.), The Proceedings of the 12th International Congress

on Mathematical Education, DOI 10.1007/978-3-319-12688-3_39
} 
research has looked at proof teaching in classroom contexts and considered implications for the curriculum. The social-cultural aspects revealed in these studies motivate a current branch of research which is offering new insights. Comparative studies, trying to come to a better understanding of cultural differences in student's arguing and in the teaching of proof can be seen as part of this new branch of research. In this respect, papers presented at ICMI study 19 on "Argumentation and Proof" illustrate this diversity. Differences concern the focus researchers take in their approach, as well in the methodological choices they make. This leads not only to different perspectives, but also to different terminology when we are talking about phenomena. Differences are not always immediately clear, as we sometimes use the same words but assign different meanings to them. On the other hand, different categories that we build from empirical research in order to describe students' processes, understandings and needs are rarely discussed conceptually across the research field. Conceptual and terminological work is helpful in that it allows us to progress as a community operating with a wide range of research approaches.

Eleven papers and seven posters have been presented during the four sessions. There were thirty-five non-presenting participants who attended at least one session. The papers were from: Hong-Kong (1), Japan (2), Japan and UK (1), Turkey (1), UK (1), USA (5). The posters were from: Canada (1), Colombia (1), France (1), Japan (1), Peru (1), USA (2). The non presenting participants came from: Denmark (1), France (2), Germany (2), Hong-Kong (1), Japan (5), Korea (10), Norway (1), Portugal (1), South Africa (1), Sweden (3), Thailand (2), UK (1), USA (4).

For each session the attendee ranged from forty to fifty participants. The composition of the attendee was representative of the diversity of the participants in the congress: mathematicians, didacticians, expert researchers as well as young researchers, teachers form primary school to university.

According to the topics addressed by the papers accepted we identified four main themes to which each paper and poster may be related:

- Theme 1: Conception of proof from different theoretical perspectives.

- Theme 2: Proof in the classroom: the role of the teacher.

- Theme 3: Evaluation of proofs.

- Theme 4: Curriculum and materials.

Each of the four 90-min sessions (July 2013 10th, 11th, 13th, and 14th) were devoted to one of these themes. The structure for each 90-min session included some brief opening remarks by the chair of the session; the presentations, 10-min for long presentation and $5 \mathrm{~min}$ for short presentations. The general discussion on the papers and posters took place at the end of each session. 


\section{Theme 1: Conception of Proof from Different Theoretical Perspective (10th July 2013)}

In this session, three papers were presented, so that two related posters, presenting a variety of theoretical backgrounds.

Kotaro Komatsu (Japan), in line with a long tradition of considering Lakatos epistemology as relevant for mathematics education, proposed to consider Lakatos ' Heuristic Rules as A Framework for Proofs and Refutations in Mathematical Learning: Local Counterexample and Modification of Proof. Ysuke Tsujiyama (Japan) paid interest to characteristization of proving process in school mathematics based on Toulmin's concept of field, while Michelle Zandieh, Kyeong Hah Roh, Jessica Knapp (USA) explore Student Proving through the Lens of Conceptual Blending.

In their posters, Paul Dawkins, Kyeong Hah Roh (USA) emphasized the Roles of Metaphors for Developing Students' Logical Control in Proof-oriented Mathematics, while Shiv Karunakaran (USA) considered Examining the Structure of Proving of Experienced Mathematics Doctoral Students.

The final discussion enlightened the diversity of the theoretical perspectives; questions were addressed from teachers to researchers on the relevance of their theoretical backgrounds for designing tasks aiming to develop reasoning, proof and proving in class.

\section{Theme 2: Proof in the Classroom: the Role of the Teacher (11th July 2013)}

In this session three papers and one poster were presented; various aspects of the delicate role of teachers in classroom concerning proof have been enlightened.

Annie and John Selden presented the paper from Milos Savic (USA) who considers the controversial question Where is the Logic in Student-Constructed Proofs? Andreas J. Stylianides and Gabriel J. Stylianides (U.K.) focused on "The big hurdle we have to overcome is getting students out of the mode of thinking that math is just plug-in-and-move-on kind of thing": Challenges in beginning to teach reasoning-and-proving. Anna Marie Conner (USA) considered Warrants as Indications of Reasoning Patterns in Secondary Mathematics Classes.

In his poster, Medhat H. Rahim (Canada) proposed to consider Description and Interpretation of Student-Teachers' Attempts to Construct Convincing Arguments and conjectures through Spatial Problem Solving Tasks. 
The discussion in the session, along with the content of presentation, put light on the difficulties for teachers to engage students in mathematical activity involving proof and proving; a main issue concerns the possibility of making students aware of the necessity for proof and proving. Taking in consideration that Geometry was the most represented mathematical domain in the papers and posters presented in the group, a question raised in the discussion: is this matter of fact unavoidable, or is it possible to work on proof in class in other mathematical domains. Finally participants agreed that although geometry is a relevant traditional domain for teaching reasoning, proof and proving in secondary school in many countries, there are also other relevant domains such as arithmetic, linear algebra, analysis etc., depending on the level.

\section{Theme 3: Evaluation of Proofs (13th July 2013)}

Two papers and two posters were devoted to evaluation of proofs or arguments. A third poster related to the theme 2 was also presented.

Yeşim İmamoğlu, Ayșenur Yontar Toğrol (Turkey) have presented An Investigation of Senior Mathematics and Teaching Mathematics Students' Proof Evaluation Practices. Yating Liu, Azita Manouchehri (USA) focused on means for Nurturing High School Students' Understanding of Proof as a Convincing Way of Reasoning and look for a theoretical framework.

In their posters, Shintaro Otsuka (Japan) paid interest on Reasoning in Explaining False Statements: Focusing on Learner's Interpreting Propositions, while Viviane Durand-Guerrier, Thomas Barrier, Faiza Chellougui, Rahim Kouki (France, Tunisia) provided An Insight on University Mathematics Teaching Practices about Proofs involving Multiple Quantifiers. Maria Nubia Soler Alavarez (Colombia) presented Types of Rasoning used by Training Mathematics Teacher in a Class about Rational Numbers.

Questions concerning validity were at the core of this session. The papers showed the variety of practice related to this question, opening a discussion on the distance between requirement addressed to students concerning rigor and ordinary teachers practices which generally do not fulfill these requirements. Finding an adequate balance between these two aspects in class is not easy.

\section{Theme 4: Curriculum and Materials (14th July 2013)}

In this session, three papers and one poster were presented, providing a variety of landscapes.

Mikio Miyazaki, Taro Fujita, Keith Jones (Japan, U.K.) presented material for Introducing Proof in Lower Secondary School Geometry: A Learning Progression Based on Flow-chart Proving. Yip-Cheung Chan (Hong-Kong) aim Rebuilding The 
Harmony Between Figural and Conceptual Aspects For Reasoning, Proof and Proving in Dynamic Geometry Software. Ruthmae Sears (USA) investigates The Impact of Subject-specific Curriculum Materials on the Teaching of Proof and Proof Schemes in High School Geometry Classrooms. Estela Vallejo and Uldarico Malaspina (Peru) offered A Look at the Justifications in the Basic Education in Peru: the National Curricular Design and some Texts used in the 1st Grade of Secondary level.

The discussion on the presentations concerned the diversity of approach in curriculum and material, enlightening the interest of comparative studies on reasoning, proof and proving.

As closing remarks, the participants agreed that the discussion which took place at the end of each session were rich and concerned as well the implication for teaching, the theoretical assumptions, the role of logic, the specificity of geometry, the need for proof or proofs without words.

A common feeling was that, although Reasoning Proof and Proving have been studied for a long time, further international researches are needed.

Open Access This chapter is distributed under the terms of the Creative Commons Attribution Noncommercial License, which permits any noncommercial use, distribution, and reproduction in any medium, provided the original author(s) and source are credited. 